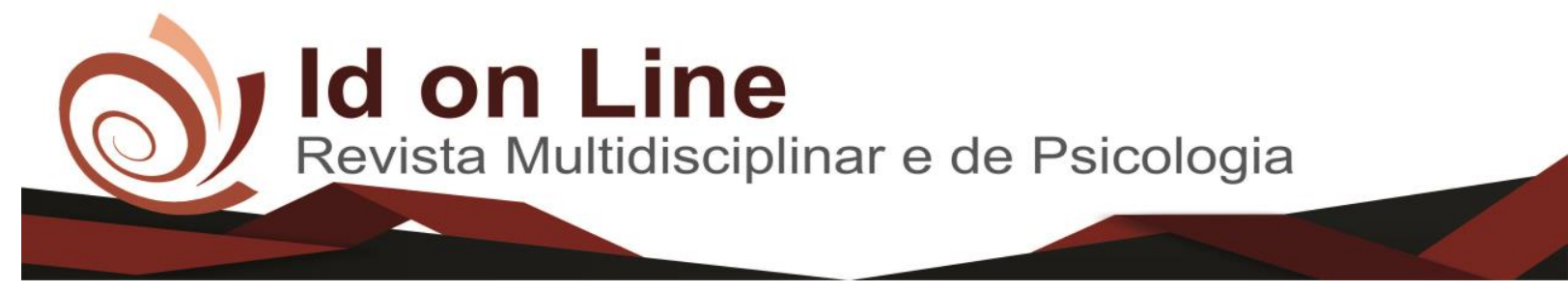

Comment

\title{
O Autismo e as Dificuldades no Processo de Aprendizagem Escolar
}

Mônica Misleide Matias Ferreira ${ }^{1}$; Aurenia Pereira de França ${ }^{2}$

Resumo: Este artigo aborda sobre a temática do autismo e as dificuldades no processo de aprendizagem escolar, ressaltando o ensino aprendizagem e adaptação a escola. De modo que, desenvolva adequadamente as competências cognitivas e sociais das crianças autista. $\mathrm{O}$ artigo em pauta objetivou-se a compreender o processo de aprendizagem da criança autista no ambiente escolar. A metodologia utilizada para desenvolver o presente estudo é de ordem bibliográfica, uma pesquisa qualitativa de autores renomados como: Mantoan (2006), Varella (2011), Wendell (2013), Orrú (2013), Mello (2013) entre outras fontes. Observou-se que é de grande relevância o tema em questão, para que profissionais, familiares e a sociedade compreenda como se dá a aprendizagem de criança portadora de autismo. A criança autista necessita de métodos e acompanhamento especializado.

Palavras - chave: Autismo. Ensino e Aprendizagem. Família. Escola

\section{Autism and Difficulties in School Learning Process}

\begin{abstract}
This article addresses the issue of autism and difficulties in the school learning process, emphasizing teaching learning and adaptation to school. So, properly develop the cognitive and social skills of autistic children. The present article aimed to understand the learning process of the autistic child in the school environment. The methodology used to develop the present study is a bibliographical one, a qualitative research of renowned authors such as: Mantoan (2006), Varella (2011), Wendell (2013), Orrú (2013), Mello (2013) among other sources. It was observed that the theme in question is of great relevance, so professionals, family members and society understand how the learning of children with autism occurs. The autistic child needs specialized methods and accompaniment.
\end{abstract}

Keywords: Autism. Teaching and learning. Family. School.

\section{Introdução}

Através de observações apreciadas, em relatos de autores da educação, busca-se averiguar as dificuldades de aprendizagem, adaptação e métodos de ensino para alunos autistas no Ensino Fundamental - Anos Iniciais. Descrito pelo psiquiatra Leo Kanner, em 1943, como distúrbio, apresentando incapacidade para se relacionarem com outras pessoas e situações desde o início da vida. Sendo assim, como se dá o processo de aprendizagem do aluno autista?

O estudo deste trabalho teve como objetivo geral, compreender o processo de aprendizagem da criança autista no ambiente escolar, pontuando elementos e estratégias que

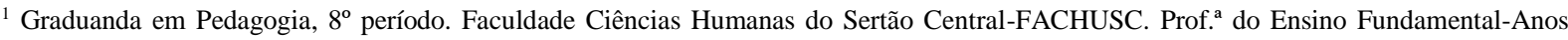
Iniciais. E-mail: monicamisleide@hotmail.com

${ }^{2}$ Especialista. em Metodologia do Ensino. Especialista. em Ciências da Educação e Supervisão Pedagógica e Mestranda em Ciências da Linguagem pela UNICAP.
} 
possam ajudar a família, o professor e a criança a enfrentar os desafios. Deste modo apresentase como objetivos específicos, refletir sobre a importância do ensino destas crianças, inserindoas na sala de aula do ensino regular.

Existe um programa educacional que tem como função atender os alunos com algum tipo de dificuldade de aprendizagem, inclusive crianças portadoras do espectro autista(TEA). Esse programa que é realizado em escolas da rede regular de ensino tem por nome de Atendimento Educacional Especializado (AEE), que atendem as crianças em horário extra, reforçando o trabalho realizado pela professora na sala de aula, (BRASIL, 2009).

$\mathrm{O}$ aspecto levantado para este trabalho, vem da necessidade para o ensino e a aprendizagem do aluno autista dentro da sala de aula. Assentado nestas informações, atualmente utiliza-se três procedimentos indicados para o processo de aprendizagem das crianças autistas: ABA - análise aplicada do comportamento; PECS - sistema de comunicação através de trocas de figuras e TEACCH - programa de aprendizagem individual; metodologias pedagógicas abordadas no artigo que segue.

A escola precisa ser inclusiva e adaptar métodos e profissionais capacitados, planejando um sistema de educação flexível respondendo as necessidades e diversidades de cada criança (MANTOAN, 2006, p.25). Inserir uma criança Autista em uma sala de aula do ensino regular, requer uma série de demandas, para favorecer o bem estar e a adaptação correta do educando, por ser uma criança que necessita de cuidados específicos, este foi o assunto pelo qual instigoume , sendo bastante difícil o aprendizado dessas crianças com Autismo em salas de aula do Ensino regular, ainda nesta mesma linha, vem as dificuldades de profissionais qualificados, para realização de um trabalho necessário para aprendizagem das crianças portadoras de Autismo, problema pelo qual ressaltei a minha pesquisa, definindo uma intervenção adequada à problemática da criança com transtorno autista, e a participação ativa da família e do professor, é de suma importância para inseri-la e ter a certeza que irá ser inclusa em todas as atividades, de acordo com seus limites, participar de todas as atividades propostas na sala de aula, agindo e interagindo em prol do bem estar e desenvolvimento da criança.

Baseando-se nisso, o presente estudo discorre acerca dos seguintes tópicos: Definições e conceitos do Autismo, o autismo no contexto escolar, a inclusão do autista e aprendizagens significativas, participação da família e escola auxiliando no ensino aprendizagem da criança autista. 


\section{Definições Conceitos do Autismo (As causas e Sintomas do Autismo).}

Autismo é um distúrbio de origem orgânica, lesão encefálica de componente genético que através de algumas atitudes e comportamentos da criança ela pode ser diagnosticada como autista. O psiquiatra Leo Kanner (1943), em seu artigo descreveu como uma síndrome (conjunto de sintomas) que varia do grau severo ao brando, sendo desenvolvido tipicamente aos três anos de idade, comprometendo todo o desenvolvimento psiconeurológico da criança. Mesmo sendo observados alguns eventuais sintomas, necessita-se de um profissional para dar um diagnóstico preciso do autismo. Observar a criança até os três anos de idade é de suma importância, pois nascemos com cem bilhões de neurônios que com o passar do tempo, uns se desenvolvem e outros vão sendo destruídos ou seja quebrados de acordo com desenvolvimento de cada ser. Os neurônios vão se moldando e chegamos à fase adulta somente com vinte bilhões de neurônios, Bryson e col. (cit. por Mello, 2005) um autor que realizou um estudo sobre o assunto no Canadá, estimou que a cada mil crianças uma nasce com sintomas ou desenvolve o autismo.

Uma criança com autismo nasce com mais neurônios do que uma criança não autista que podem ser diagnosticados mesmo na gestação. Com isso a parte pré-frontal do cérebro que é a parte que armazena algumas informações importantes não se desenvolvem e se torna pesada dificultando o desenvolvimento dos neurônios esses neurônios são chamados de espelho, vão se quebrando e não se desenvolvem. Segundo Olivier, (2008) conceitua:

[...] O autismo é entendido como um distúrbio que pode variar do grau leve ou severo, sendo considerado como limitrofia, em casos leves. Alguns podem ser diagnosticados com como individuo com traços autísticos, e, entre outros também podem ser vistos como portadores da síndrome de Asperge, que é considerada por muitos como um tipo de autismo com inteligência normal. (OLIVIER, 2008, p. 12)

O autor relata alguns tipos de Autismo, que necessita ser diagnosticado com muitos estudos e pesquisas, o autista vive em um mundo só deles onde não existe um objetivo seu, crianças com esse tipo de transtorno geralmente não gostam de ser abraçados, relata o psiquiatra da Áustria, Leo Kanner(1943), sendo que em suas descobertas, descreveu um grupo de onze casos clínicos de crianças em seu artigo originalmente intitulado Transtornos autistas do contato afetivo, utilizando-se da mesma expressão, pois as crianças investigadas por ele apresentavam incapacidade para se relacionarem com outras pessoas e situações desde o início da vida, falha no uso da linguagem para comunicação, estereotipias e resistência à mudanças. 
Apesar das causas do autismo ainda ser desconhecidas, existem alguns problemas neurológicos ou genéticos que foram ligados ao autismo, como por exemplo: contágios depois do nascimento, como herpes simplex, contágios antes do nascimento como a rubéola, sífilis, transmitida via placentária, toxoplasmose e intoxicações diversas. Pode- se começar a observar alguns pequenos sinais do autismo nas crianças a partir de um ano e seis meses, até os três anos de idade. Um diagnóstico seguro só mesmo a partir dos três anos de idade. VARELLA (2011), reforça que:

O diagnóstico do autismo, nem sempre é fácil de ser conseguido, é clinico feito através de observações direta do comportamento e de uma entrevista com os pais ou responsáveis. Os sintomas costumam estar presentes entre três anos de idade, sendo possível fazer o diagnóstico por volta dos dezoitos meses de idade. (VARELLA, 2011, p. 32)

Os indícios do autismo na criança podem despontar quando: escuta determinadas coisas e outras não; Não estende os braços para seus progenitores; não esboça alegrias, sentimentos e nem olha diretamente no olho da outra pessoa; tem dificuldade de se comunicar, não aponta com os dedos; Não chora quando se fere ou cai; Não gosta de brincar com os seus brinquedos; opta por ficar isolada; Não brinca com outras crianças; Não fala; a sua linguagem é repetida; seus movimentos são repetitivos e frequente, como balanceamento, dentro outros. Observando estes comportamentos nas crianças, os pais precisam informar ao pediatra, nas consultas médicas.

Não tem cura para o autismo, mas existem meios que estimulam a criança a aperfeiçoar sua aprendizagem e modo de se comportar. Identificando os sintomas, poderá ajudar uma criança autista.

\section{O Autista no Contexto Escolar}

As crianças autistas sentem dificuldade em se adaptar em espaços educacionais. Os problemas encontrados são: socialização, organização, distração e dificuldade em sequenciar. Levando em consideração à grande insuficiência de qualificação profissional para o correto diagnóstico e acolhimento à criança autista, as instituições de ensino padece ao receber este aluno. 
Estas crianças têm dificuldades ao nível da partilha, apesar de muitas destas crianças terem aprendido em casa a partilhar com os irmãos. No jardim de infância, é necessário ensinar a criança a partilhar com os outros meninos (CUBEROS,1997, p.93)

Neste contexto, encontra-se diversas áreas a interferir na aprendizagem destas criança: definição de objetivos educacionais e avaliação, intervenção na área de comunicação interação, intervenção na área cognitiva e nos problemas de comportamento. Com os objetivos educacionais e avaliação, almeja verificar à forma de aprendizagem das criança. Elas parecem saber fazer algumas coisas, mas tem muita dificuldades em conseguir concretizar as atividades. Como estas crianças não toleram a frustração quando não conseguem realizar uma tarefa, os educadores têm que arranjar estratégias para conseguirem acalma-las, um dos meios é através da música (Cuberos, M.D.A; Garrido, A.A; et alli; (1997); Página: 255).

Visto que, são vários os tipos de autismo, suas particularidades podem variar e por conseguinte o processo de aprendizagem, então há a necessidade de adequação da prática pedagógica para esta criança. Como menciona Santos (2008), os autistas do tipo Aspergers, por exemplo, falam impecavelmente, até sem erros; mas sentem a dificuldade em utilizar a linguagem para se relacionar socialmente, os empecilhos para a comunicação são falta de ânimo para se relacionar com o meio e o foco de interesse limitado. No Brasil já é utilizado três métodos de ensino, com o objetivo de atender as necessidades do autista.

Segundo Mello (2001) o ABA, analise aplicada do comportamento, são ensinadas competências relacionadas ao desenvolvimento, como: cognição, socialização, linguagem e habilidade motora. De acordo com a autora citada acima (2001, p.21), "esse método é muito criticado, supondo que tornar as crianças robôs, o que de certa forma é correto, pois a ideia é intervir o máximo possível, para gerar o desenvolvimento da mesma." A esse método acoplase o PECS, uso funcional de figuras de comunicação, é simples e de baixo custo, onde através de cartões ajuda a desenvolver a linguagem verbal da criança e o método TEACCH, forma de avaliação qualificado como um programa de aprendizagem individual. Segundo Cornelsen (2007), este é um grande aliado do professor que busca ação positiva no processo de aprendizagem do aluno autista, trabalha com o autista e todos que o envolve. Afirmam Gomes e Silva:

Neste método a programação individual de cada aluno é uma das ferramentas essenciais, pois possibilita o entendimento do que está ocorrendo, propicia confiança e segurança. As dificuldades de generalização indicam a necessidade de rotina clara e previsível. Indica visualmente ao estudante quais tarefas serão 
realizadas, além de instrumento de apoio para ensinar o que vem antes, o que acontece depois, proporcionando o planejamento de ações e seu encadeamento numa sequência de trabalhos. (GOMES E SILVA ,2007, p.3)

Nesse sentido é necessário que o docente tenha bastante calma e compreensão para com o aluno autista, para que ele consiga assimilar; o autista pode mostrar-se distante, não atender a chamado e até mesmo ter grande atraso para aprender determinada explicação. Mas nada disso ocorre porque a criança não possui interesse e sim porque o autismo afeta e adia o processo de aprendizagem, ela necessita de muita motivação e cuidado para desenvolver sua intelectualidade. A criança autista, não explora o brinquedo como deveria, ela simplesmente se interessa por um único movimento, podendo ficar horas a fio rodando a roda de um carrinho, por exemplo, além disso, é resistente a mudança de rotinas e o professor precisa estar atento e planejar suas aulas de acordo com todas essas necessidades, para que a criança não se sinta excluída entre seus colegas que por sua vez, precisa estar ciente das dificuldades que a criança tem, ou seja, será um trabalho em conjunto de toda a comunidade escolar, para que essa criança não seja rotulada e estabelecendo metas, partindo sempre do que ela é capaz de fazer e aprender.

É esplendido como o vínculo afetivo com o professor são essenciais para motivar a criança na sala de aula que ela está inserida, mesmo com o seu auxiliar que é um direito seu ter essa assistência, o professor precisa sempre buscar e manter contato com o aluno, estimulando a comunicação e a inclusão com todas as crianças do ambiente, propondo atividades inclusivas e participar ativamente com eles em todas as atividades propostas, com isso o aluno se sentirá seguro e propício a tudo que lhe for oferecido e ensinado, mesmo com a dificuldade que lhe acomete a participação do professor será satisfatória, não só para a criança com autismo, mas também para todas da sala de aula, partindo desse pressuposto. Wendel, (2013), relata que:

\footnotetext{
Nossos sentidos de educador devem estar direcionados ao coração dos educandos. É nele que está a resposta para uma aprendizagem viva. No encontro em sala de aula, deve-se buscar cotidianamente algo necessário para o desenvolvimento humano dos educandos: A abertura do seu coração. É está inteiro nesse encontro de conexão em sala de aula. São dois seres abertos para aprender. (WENDEL, 2013, p. 10).
}

Com tudo a contribuição do professor, junto às atividades propostas enriquece e levanta a autoestima da criança contribuindo assim para o seu aprendizado mediando e participando das brincadeiras entre o grupo, dialogando em uma linguagem clara e objetiva, utilizando sempre todos os recursos disponíveis para ensinar com qualidade e sabedoria, afinal um bom 
professor tem que ser pesquisador, facilitando a aprendizagem da criança, inclusive do autista, penetre no mundo autista para entender, aprender e compreender como esta criança aprende.

Nota-se que para muitas destas crianças o estimulo auditivo, visual ou tátil pode reforçar seu desenvolvimento, controlando seu comportamento e sua atenção durante as atividades. Sendo fundamental ter recursos e matérias adequados, facilitando a aprendizagem e motivando sua atenção na realização das atividades propostas.

\section{A Inclusão do autista e aprendizagens significativas}

A inclusão da criança com autismo no ensino regular gera uma série de situações, que a legislação que regulamenta o acesso da criança a escola, não prevê. Perante esta realidade, surge a questão: o professor, diante da manifestação do transtorno e da cobrança da instituição por resultados, encontra-se preparado para realizar a educação e promover o desenvolvimento deste aluno.

\footnotetext{
A elaboração e a execução do plano de AEE são de competências dos professores que atuam na sala de recursos multifuncionais ou centros de AEE, em articulação com os demais professores do ensino regular, com a participação das famílias e em interface com os demais serviços setoriais da saúde, da assistência social, entre outros necessários ao atendimento (BRASIL, 2009).
}

Outro aspecto levantado por este autor discorre que a principal característica deste método é a participação do pesquisador como interpretador da realidade, que é construído de acordo com as informações obtidas mediante os dados presentes no questionário. Para delimitar-se a análise da pesquisa, optou-se por organizar as respostas identificando-as por educadores, a primeira questão vem a ser, como define o autismo? Resumidamente é uma síndrome em que indivíduo apresenta dificuldade na interação, linguagem e criatividade, ainda é um desafio compreender o autismo, visto a amplitude de funcionamento de cada um onde o autismo se manifesta de formas e graus diferentes sempre há aprendizagens significativas no meio autista, pois em relação ao diagnóstico, o quanto antes definido, maior a possibilidade de realizar intervenções pedagógicas, aumentando assim o desenvolvimento social, cognitivo e áreas afins.

Para Maria Teresa Mantoan(2006), pedagoga, mestra e doutora da Universidade de Campinas (Unicamp) especialista em inclusão, o cenário educacional brasileiro atual tem como 
frase principal o acesso, permanência e sucesso de toda criança na escola regular. A pedagoga assegura que a condição se consolida como desafio, posto que a escola atual não é feita para todos. Mantoan 2006, ressalta que:

\footnotetext{
$\mathrm{Na}$ verdade resiste-se a inclusão escolar porque ela nos faz lembrar que temos uma dívida a saldar em relação aos alunos que excluímos, sabemos que alunos com ou sem deficiência, que foram ou são excluídos das escolas comuns, devem estar inseridos e há muito tempo, ou seja, desde que a ensino fundamental é obrigatório para os alunos em geral. (MANTOAN, 2006, p.25)
}

Partindo do pressuposto que indaga a autora, a família não deve e não pode excluir a criança do meio escolar e os profissionais em educação devem amparar esse estudante a satisfazê-lo diante de uma prática pedagógica direcionada a sua capacidade de aprendizagem e proporcionando atividades de intervenção e desenvolvendo projetos alternativos para a correção das dificuldades de acordo com o nível de cada criança, melhorando assim o rendimento educacional do educando.

Os objetivos do método são: habilitar crianças portadoras de autismo a se comportar de forma ativa e independente; atender adequadamente portadores de autismo e suas famílias e incluindo os próximos a eles; oferecer conhecimentos clínicos teóricos e práticos sobre o autismo; divulgando informações importantes através do treinamento e publicações. Ensinar coisas útil para a criança autista é o principal objetivo de um trabalho adequado e a perseverança é um bom aliado deste objetivo. Toda tarefa de interação da criança com objetos e com circunstâncias do meio deve ser feito simultaneamente ao trabalho de capacitação, aos cuidados pessoais e ao lazer para o processo de aprendizagem e aceitamento de normas.

\section{A participação da família e escola na contribuição da aprendizagem da criança Autista.}

A criança autista deve ter uma assistência considerável da família, onde ao inseri-la no âmbito escolar precisa relatar o diagnóstico do filho, para que o professor fique ciente de tudo que lhe acomete. Em muitos casos as famílias não aceitam que a criança possa ter autismo e indagam relatos de que a criança é impulsiva; a criança com autismo necessita ser assistida por 
uma equipe de especialistas, sendo papel exclusivo da família a procura do tratamento adequado para essa criança, segundo MELLO (2013):

\begin{abstract}
A despeito das diferenças entre os indivíduos que recebem o diagnóstico de autismo, uma característica é comum à imensa maioria de seus familiares: desespero e esperança por uma cura milagrosa. Essa é uma combinação mágica para a vulnerabilidade. Os pais da criança que recebe o diagnóstico de autismo, torna-se altamente vulnerável a promessas de curas milagrosas e tratamento sem sustentação em evidencia. (MELLO, 2013, p. 82)
\end{abstract}

É de suma importância a contribuição da escola no ensino aprendizagem de crianças Autista, é essencial que o ambiente escolar seja o caminho para melhorias das práticas e métodos que facilitem o ensino aprendizagem da criança com esse tipo de transtorno. Diante de várias dificuldades, necessita implementar no seu currículo, projetos específicos e direcionados para a aprendizagem e aceitação de crianças Autista na escola, é uma tarefa nada fácil, mas se não lutarmos por esse objetivo não mudaremos esse quadro.

Porém, mesmo diante de todas as leis e debates que asseguram que a criança Autista deve ser incluídas nas salas de Ensino Regular, ainda falta muito para que de fato ela aconteça. Tomadas de decisões necessárias precisam ser asseguradas e a escola facilita essa precisão. Pois muitas vezes, o que está escrito no capítulo V da LDBEN (1996), não se adéqua à realidade das escolas que realizam o atendimento educacional especial. A Lei que assegura esse direito garante adequação das escolas desde o espaço físico ao currículo, acrescentando no seu Projeto político as necessidades da criança autista, bem como promover projetos que envolva toda a comunidade escolar, fazendo-a entender, que as crianças não são diferentes e necessitam do apoio de todos. Ao falar da criança Autista o autor Orrú retrata o seguinte:

\footnotetext{
Assim como qualquer um de nós, a pessoa com Autismo tem sua individualidade, desejos e necessidades que vão além das características da síndrome. Logo, nem tudo, que venha a dar resultado para uma pessoa com autismo, serve de referência positiva a outra pessoa com a mesma síndrome. (ORRÚ, 2011, p. 32)
}

Assim sendo, entende-se que não é porque uma atividade deu certo com um que irá fazer o mesmo efeito e ter o mesmo resultado com outro, as crianças não são iguais e as necessidades são diferentes, com isso a escola juntamente com o professor e o coordenador pedagógico tem a precisão de fazer um trabalho em equipe, para sanar as necessidades de todos e possam está analisando as aulas e as atividades que facilitem o trabalho do educador e quanto o 
desenvolvimento educacional da criança, inseri-la uma sala regular de ensino, é necessário que a prática educativa utilizada pela professora, atenda às necessidades do aluno autista; para que o trabalho do professor obtenha sucesso, ele precisa do total apoio da escola, que por sua vez necessita ter em seu espaço a sala de atendimento, que é uma sala específica para o trabalho com atividades adequadas para a criança autista, onde ele terá seu primeiro contato com a escola e dependendo do seu desenvolvimento, o seu progresso ele é integrado nas salas de ensino regular.

Destarte, a escola fazendo o seu papel facilitará de forma significativa o trabalho do professor junto à criança autista sendo que a sala de atendimento ou sala de recurso é de suma importância para a criança, já que funciona em um horário diferente das do ensino regular, funcionado como reforço escolar para essas crianças, trazendo benefícios para o seu aprendizado.

Por esse motivo, mais do que a aprendizagem em si, é indispensável oferecer um ensino de qualidade. É fundamental um plano de ensino que respeite a capacidade de cada aluno e que proporcione atividades diversificadas, considerando o conhecimento que cada aluno traz para a escola. Especialistas sugerem que os conteúdos em debate sejam fundamentais para o desenvolvimento da criança autista. Nesse caso, o que está em jogo são as disposições do autista. É nelas que se deve investir para, assim, desenvolver essa ausência de habilidades, sendo necessário esperar um desempenho oferecido, ao que a maioria dos indivíduos do espectro autista não corresponde, pois cada criança reage de um jeito. Enquanto as crianças realizam anotações comuns, os autistas fazem fluxogramas sobre o conteúdo escolar, facilitando assim o seu aprendizado em relação ao que vem sendo utilizados por seus colegas. Nilsson, defende que:

[...] ao usar a ideia de um programa diário visual individual, é fazê-la conter somente atividades enfadonhas que os alunos já conhecem, sempre apresentadas na mesma ordem. Assim a ideia perde sua função para a pessoa envolvida. Temos de pensar no que poderia interessante para ele, de forma que os conteúdos do dia sejam um acordo entre as coisas que julgamos que ele precisa fazer e coisas que ele prefere fazer. (NILSSON ,2004, p. 57)

Discorrer sobre educação inclusiva é ao mesmo tempo falar do ensino dentro da sala de aula, onde os alunos aprendem com os demais; em uma verdadeira escola inclusiva, os alunos não precisam se deslocar da sala de aula para receberem ajuda especializada, recebe-se no interior da classe. De acordo com alguns especialistas, a educação inclusiva não baseia em 
baixas expectativas relacionadas aos educandos, mas, na importância de gerar situações instigantes que provoque aprendizagens considerável para todos os alunos.

Outro ponto de grande significância para a melhoria do ensino seria a capacitação dos professores e das escolas para trabalharem um currículo que atenda as exigências, sendo um grande desafio para as escolas e professores; muitos ainda utilizam o método tradicional. Planejar o aprendizado e a participação dos alunos dentro da sala de aula sem aderir ao ensino tradicional, é adquirir novos conhecimentos para a inclusão de crianças autistas nas salas de aula do ensino regular, procurar as melhores formas de modificar o currículo de acordo com a necessidades de cada criança, planejar em articulação com outros profissionais da educação, ser dinâmico quanto a produção de materiais curriculares, a observação mútua de aulas, incentivarem a experimentação e inovação pedagógica, são alguns itens essenciais que a escola inclusiva impõe aos professores nas suas práticas. Segundo Nunes (2008, p.4):

\footnotetext{
As crianças com autismo, regra geral, apresentam dificuldades em aprender a utilizar corretamente as palavras, mas se obtiverem um programa intenso de aulas haverá mudanças positivas nas habilidades de linguagem, motoras, interação social e aprendizagem é um trabalho árduo precisa muita dedicação e paciência da família e também dos professores. É vital que pessoas afetadas pelo autismo tenham acesso a informação confiável sobre os métodos educacionais que possam resolver suas necessidades individuais. (NUNES,2008, p. 4).
}

Nesta perspectiva o currículo escolar necessitará ser ajustado com adaptações adequadas para os professores. Feitos as modificações no currículo, os professores devem estudar, analisar a metodologia que aplicam nas suas intervenções diárias, tentar encontrar métodos, táticas de ensino promotoras de inclusão, desenvolvendo nas crianças, atitudes de igualdade, de oportunidades. Apresentando uma mudança de pensamento positivo desde cedo, estará a construir uma sociedade inclusiva que vai se multiplicando de maneira favorável para inclusão das crianças autistas na escola.

\section{Considerações Finais}

Existem inúmeras formas de ajudar o autista, a fundamental é entender suas necessidades e trabalhar suas dificuldade para se chegar a uma aprendizagem. O programa de assistência deve ser essencialmente prático e cômodo, atendo cada uma de forma 
individualizada. $\mathrm{O}$ autista processa de forma diferente, mas vive no nosso mundo. $\mathrm{O}$ desenvolvimento da criança autista é muito lento, precisa de grande atenção, elogios e motivação. Família e educadores juntos devem incentivar a criança, mostrar que podem aprender.

Revestiu-se o processo entre família e escola, para o bom desempenho social e intelectual da criança autista e a atuação do professor através das práticas pedagógicas para o desenvolvimento da criança com esse tipo de transtorno que afeta o lado emocional da família, que se preocupa com essa sociedade cheia de preconceitos em todos os sentidos, com isso afeta a vida da criança e de todos os seus familiares.

É importante salientar, que é de grande relevância a abordagem e as informações descritas nesse documento, para ajudar familiares e profissionais da espaço educacional a distinguir uma criança autista e direcionar aos profissionais especialistas na área para um diagnóstico correto.

Pode-se afirmar através da pesquisa bibliográfica discutidas neste artigo, que embora o autista apresente grande dificuldade para se relacionar social e para se desenvolver intelectualmente é provável que se torne uma indivíduo que convive perfeitamente em sociedade, evoluindo na aprendizagem como qualquer outro estudante ou muito mais, quando se descobre sua potencialidade. Só precisa ser diagnosticado, aceito pelo família e ter acompanhamento especializado.

Ressalvo ainda, que ao longo dessa pesquisa, os desafios encontrados para as crianças com algum tipo de necessidade especial, ainda são problemas de adaptação. As escolas precisam e a sociedade precisa estar preparada, aceitando as diferentes forma de aprendizagem, para que este seja de fato incluído e compreendido.

\section{Referências}

CUBEROS; Garrido; (1997; p. 93).

BRASIL. Diretrizes Operacionais do Atendimento Educacional Especializado na Educação Básica, modalidade Educação Especial. Brasília, 2009.

CORNELSEN, Sandra. Uma criança autista e sua trajetória na inclusão escolar por meio da psicomotricidade relacional. Universidade federal do Paraná, 2007 Curitiba. 
GOMES, Alice Neves, SILVA, Claudete Barbosa da. Software Educativo para Crianças Autistas de Nível Severo. In: $4^{\circ}$ Congresso Internacional de Pesquisas em Design, 2007, Rio de Janeiro.

MELlO, Ana Maria, S, Ros de Andrade, Maria América Ho Helena Sousa Dias, Inês de. Retratos do Autismo no Brasil. $1^{\circ}$ Edição, São Paulo. Editora. AMA,2013, p.82

NILSSON, Inger. Introdução a educação especial para pessoas com transtornos de espectro autísticos e dificuldades semelhantes de aprendizagem. Em PDF. Congresso Nacional sobre a Síndrome de Autismo 2004. Disponível em <http://www.ama.org.br/download/Autismo-IntrodEducEspecial.pdf> Acesso em: 23 mar.2009.

NUNES, Daniella Carla Santos. O pedagogo na educação da criança autista. Publicado em 07 de fevereiro de 2008.

ORRÚ, Ester Silva. Autismo: o que os pais devem saber? - 2. ed. - Rio de Janeiro: Wak Editora, 2011.p.32

MANTOAN. Maria Teresa Eglér. Inclusão Escolar. Editora ABDR. Edição, São Paulo, 2006.p.25

VARELLA， Dráuzio；2011https://drauziovarella.com.br/videos-3/videos/o-espectro-doautismo/

WENDELL, Ney. Praticando a Generosidade em Sala de aula. Editora prazer de ler. Edição Recife 2013, p.10

Como citar este artigo (Formato ABNT):

FERREIRA, Mônica M. M.; FRANÇA, Aurenia P de. O Autismo e as Dificuldades no Processo de Aprendizagem Escolar. Id on Line Revista Multidisciplinar e de Psicologia, 2017, vol.11, n.38, p. 507-519. ISSN: 1981-1179.

Recebido: 01.10.2017

Aceito: 03.11.2017 